\title{
BMI and Risk Factors of Underweight and Obesity in HIV Subjects in Eastern Nigeria
}

\author{
Ernest Ndukaife Anyabolu1,2 \\ ${ }^{1}$ Division of Nephrology, Department of Medicine, Imo State University Teaching Hospital, Orlu, Nigeria \\ ${ }^{2}$ Division of Nephrology, Department of Medicine, Federal Medical Centre, Owerri, Nigeria \\ Email: enhealer@yahoo.com
}

Received 25 December 2015; accepted 1 March 2016; published 4 March 2016

Copyright (C) 2016 by author and Scientific Research Publishing Inc.

This work is licensed under the Creative Commons Attribution International License (CC BY).

http://creativecommons.org/licenses/by/4.0/

(c) (7) Open Access

\begin{abstract}
Background and Objectives: Human immunodeficiency virus infection (HIV) is a global healthcare problem. Progression of HIV infection is commonly associated with decreasing weight. In the early phases of HIV infection, factors associated with weight changes are not completely known. This study evaluated the body mass index (BMI) and its potential risk factors in drug-naïve HIV subjects in Owerri, Eastern Nigeria. Methodology: This was a cross-sectional study of HIV subjects. BMI was determined. Relevant investigations were performed. Potential risk factors of BMI were analyzed at different BMI categories. Association of variables with BMI and the strength of variables to predict BMI, underweight and obesity were determined. Results: The mean BMI of the HIV subjects was $26.2 \pm 5.4 \mathrm{~kg} / \mathrm{m}^{2}$. Underweight was present in $24(6.1 \%)$, overweight in 150 $(38.4 \%)$ and obesity in $84(21.5 \%)$ of the HIV subjects. High spot urine creatinine (SUCr), high 24-hour urine osmolality (24HUOsm), high serum cholesterol and high hemoglobin predicted BMI in HIV subjects. Low 24HUOsm predicted under weight, whereas low 24-hour urine protein $(24$ HUP) and high 24HUOsm predicted obesity in HIV subjects. Conclusion: The prevalence of underweight was low $(6.1 \%)$, overweight high $(38.4 \%)$ and obesity high $(21.5 \%)$ in HIV subjects. High SUCr, high 24HUOsm, high serum cholesterol and high hemoglobin were predictors of BMI in HIV subjects. Low 24HUOsm was a predictor of underweight, while low 24HUP and high 24HUOsm were predictors of obesity in HIV subjects. Abnormalities of serum lipids, renal function, and anemia were common in HIV subjects who were underweight and in those obese. Underweight HIV subjects should be evaluated at the early stages for dyslipidemia, renal damage and anemia.
\end{abstract}

\section{Keywords}

HIV, BMI, Underweight and Obesity, Prevalence, Predictors, Nigeria 


\section{Introduction}

Human immunodeficiency virus (HIV) infection is a global healthcare problem. About $70 \%$ of all people who have HIV infection live in Sub-Saharan Africa [1]. In China, the prevalence of HIV infection is 0.1\% [1], while in Kenya and Malawi, both in East Africa, it is 5\% [1]. Cameroon, a Central African country, has a similar prevalence $5.0 \%$ [1]. In Nigeria, about 3.7\% of its population has HIV infection [1].

In populations of subjects with HIV infection, weight has been a burning issue [2] [3]. Seroconversion, changes in metabolism and co-morbidities in the early phases of HIV infection have been shown to influence weight in these subjects [4]-[6]. A study has demonstrated that BMI has biphasic decline: following serocnversion, and just before AIDS development [7]. Variable prevalence of BMI has been observed in HIV subjects, with values ranging from $6.0 \%$ to $50.0 \%$ [8]-[10].

Studies on BMI in HIV subjects have shown increasing prevalence of overweight and obesity more than underweight [5] [11]. Overweight and obesity prevalence observed in some HIV subjects on antiretroviral therapy (ART) were almost the same as those found in non-HIV populations [10]-[14].

Some studies have identified some associated factors of underweight and overweight/obesity in HIV subjects; they include fever, thrush, and a CD4+ < 100 cells/ml), anemia, dietary patterns and habits [10]-[17]. Although antiretroviral therapy (ART) has influenced the pattern of weight changes in HIV subjects, factors associated with underweight, or overweight/obesity in drug-naïve individuals with HIV infection, are not completely known.

There is a paucity of reports on the prevalence of underweight and overweight/obesity and their associated factors in drug-naïve HIV subjects in Nigeria. This study was undertaken to determine the prevalence of underweight and overweight/obesity and to identify factors associated with weight changes in drug-naïve HIV subjects in Owerri, Eastern Nigeria.

\section{Materials and Methods}

This was a three-month cross-sectional, analytical study conducted in FMC, Owerri, Nigeria, in 2011. FMC Owerri, a tertiary hospital, with only one other hospital in its category in Imo state, receives referrals from the state and some neighboring states. Imo State has a population of 3,927,563; about 125,337 of these live in Owerri Municipal [18].

The subjects consisted of 393 newly-diagnosed, 18 - 65 year-old HIV-seropositive patients, consecutively recruited from an HIV clinic of the hospital.

This study was approved by the Ethical Research Committee of the hospital.

Informed consent was obtained from all the subjects who participated in this study. Demographic and anthropometric data were obtained. Investigations done included HIV screening and confirmatory tests, serum creatinine (SCr), spot urine protein (SUP), spot urine creatinine (SUCr), spot urine osmolality (SUOsm), 24-hour urine protein (24HUP), 24-hour urine creatinine (24HUCr), 24-hour urine osmolality (24HUOsm), CD4 cells count, fasting serum lipid profile (FSLP) (total cholesterol, triglyceride, high density lipoprotein cholesterol (HDL), low density lipoprotein cholesterol (LDL), hemoglobin (Hb). Exclusion criteria were increased abdominal girth from organic causes, pregnancy, and puerperium up to 6 weeks.

Creatinine was determined by modified Jeff's method, osmolality by freezing point depression using Precision System Osmette 5002 osmometer, protein by photometric method. Spot urine creatinine/osmolality ratio (SUCOR), 24-hour urine creatinine/osmolality ratio (24HUCOR) and creatinine clearance (ClCr) were determined.

\subsection{Statistical Analysis}

The data were analyzed using SPSS version 17.0 (SPSS Int. Chicago, II, USA). Statistical significance of association of variables with BMI was determined at different levels of BMI using chi square. Correlation statistics and multivariate linear regression analysis were used to determine the strength of variables to predict BMI. Further multivariate linear regression of variables with underweight, and another with obesity was done to determine the predictors of underweight and the predictors of obesity. $\mathrm{P} \leq 0.05$ was taken as statistically significant.

\subsection{Definition of Terms}

WHO classification was used to define BMI levels as follows [19]: underweight $\leq 18.5 \mathrm{~kg} / \mathrm{m}^{2}$, normal weight $=$ 
$18.5-24.9 \mathrm{~kg} / \mathrm{m}^{2}$, overweight $=25.0-29.9 \mathrm{~kg} / \mathrm{m}^{2}$, obesity class I = $30.0-34.9 \mathrm{~kg} / \mathrm{m}^{2}$, obesity class II = $35.0-$ $39.9 \mathrm{~kg} / \mathrm{m}^{2}$, obesity class III $\geq 40.0 \mathrm{~kg} / \mathrm{m}^{2}$. However, in this study, obesity was defined as class I, class II and class III obesity added together.

\section{Results}

Out of the 393 HIV subjects recruited, 1 was excluded from the study on account of errors in sample collection and incomplete data. The mean age of the HIV subjects was $39 \pm 11$ years. Females were 282 (72.0\%) and males $110(28.0 \%)$.

The mean values of variables are shown in Table 1. The mean BMI of the HIV subjects was $26.2 \pm 5.4 \mathrm{~kg} / \mathrm{m}^{2}$. Out of 392 HIV subjects, 24 (6.1\%) have BMI $<18.5 \mathrm{~kg} / \mathrm{m}^{2}, 133\left(34.0 \%\right.$ have BMI $18.5-24.9 \mathrm{~kg} / \mathrm{m}^{2}, 151$ (38.4\%) have BMI $25-29.9 \mathrm{~kg} / \mathrm{m}^{2}$ and 84 (21.5\%) have BMI $>30 \mathrm{~kg} / \mathrm{m}^{2}$.

Table 2 shows relationship between BMI and selected risk factors. There was significant association between $\mathrm{ClCr}$ and different levels of BMI in HIV subjects, $\mathrm{p}=0.026$. Out of 84 obese (BMI $\geq 30$ ) HIV subjects, 3.8\% have ClCr 30 - $59 \mathrm{mls} / \mathrm{min}$ while $35.4 \%$ have $\mathrm{ClCr} 60-89 \mathrm{mls} / \mathrm{min}$. This showed that the prevalence of obesity declined as ClCr declined. In contrast, out of 24 underweight (BMI < 18.5) subjects, $41.7 \%$ have $\mathrm{ClCr} \geq 90$ $\mathrm{mls} / \mathrm{min}$, while $58.3 \%$ have $\mathrm{ClCr} 60-89 \mathrm{mls} / \mathrm{min}$, indicating that the prevalence of underweight increased as $\mathrm{ClCr}$ declined. Among HIV subjects who have $\mathrm{ClCr} \geq 90 \mathrm{mls} / \mathrm{min}, 10$ (5.0\%) have $\mathrm{BMI}<18.5 \mathrm{~kg} / \mathrm{m}^{2}, 83$ (41.7\%) have BMI $25-29.9 \mathrm{~kg} / \mathrm{m}^{2}$, and $43(24.1 \%)$ have BMI $\geq 30 \mathrm{~kg} / \mathrm{m}^{2}$. This showed that underweight HIV subjects constituted the smallest proportion of those who have normal ClCr.

There was significant association between CD4 and different levels of BMI in HIV subjects, $p=0.017$. Out of 84 obese subjects, $94.0 \%$ have CD4 $\geq 200$ cells $/ \mathrm{ml}$ while $6.0 \%$ have CD4 $<200$ cells $/ \mathrm{ml}$. This showed that the prevalence of obesity declined as CD4 cells count declined. On the other hand, out of 24 underweight subjects, $95.8 \%$ have CD4 $\geq 200$ cells $/ \mathrm{ml}$, while $4.2 \%$ have CD4 $<200$ cells.ml, indicating also that the prevalence of underweight declined as CD4 declined. At CD4 > 200 cells/ml level, underweight were 23 (6.7\%), overweight 122 (35.6\%) and obese 79 (13.3\%). Underweight subjects constituted the smallest proportion of those with CD4 > 200 cells.ml.

There was significant association between 24HUP and different levels of BMI in HIV subjects, $\mathrm{p}<0.001$. Out of 24 subjects who were underweight, 20.8\% have 24HUP 0.150 - 0.300 g, while $54.2 \%$ have 24HUP 0.301 $3.499 \mathrm{~g}$, showing that the prevalence of underweight increased as proteinuria increased. Similarly, out of $84 \mathrm{ob}-$

Table 1. Characteristics of variables in HIV subjects.

\begin{tabular}{cc}
\hline Variables $(\mathbf{m e a n} \pm \mathrm{SD})$ & HIV Subjects \\
\hline Body Mass Index $\left(\mathrm{kg} / \mathrm{m}^{2}\right)$ & $26.2 \pm 5.4$ \\
Spot Urine Protein $(\mathrm{mg} / \mathrm{dl})$ & $11.89 \pm 19.13$ \\
Spot Urine Creatinine $(\mathrm{mg} / \mathrm{dl})$ & $137.21 \pm 98.47$ \\
SUOsm $\left(\mathrm{mOsm} / \mathrm{kgH}_{2} \mathrm{O}\right)$ & $464 \pm 271$ \\
24-Hour Urine Protein $(\mathrm{g})$ & $0.187 \pm 0.290$ \\
24-Hour Urine Creatinine $(\mathrm{mg})$ & $1507 \pm 781$ \\
24 HUOsm (mOsm) & $564 \pm 501$ \\
SUCOR (mg/dl/mOsm//kgH $/ \mathrm{O})$ & $0.422 \pm 0.486$ \\
CD4 cells & $416 \pm 209$ \\
Cholesterol (mmol/l) & $4.26 \pm 0.90$ \\
Triglyceride (mmol/l) & $1.23 \pm 0.37$ \\
HDL-C (mmol/l) & $1.18 \pm 0.39$ \\
LDL-C (mmol/l) & $2.05 \pm 0.58$ \\
Creatinine Clearance (mls/min) & $91.42 \pm 22.98$ \\
Hemoglobin (g/dl) & $11.2 \pm 1.8$ \\
\hline
\end{tabular}

SD = standard deviation, SUOsm = spot urine osmolality, 24UOsm = 24-hour urine osmolality, SUCOR = spot urine creatinine/osmolality ratio, HDL-C = high density lipoprotein cholesterol, LDL-C = low density lipoprotein cholesterol. 
Table 2. Relationship between BMI and selected risk factors in HIV subjects $(\mathrm{n}=375)$.

\begin{tabular}{|c|c|c|c|c|c|c|c|}
\hline \multirow{2}{*}{ Variables } & \multicolumn{4}{|c|}{ Body Mass Index Levels (no/\%) } & \multirow{2}{*}{$\Lambda^{2}$} & \multirow{2}{*}{ LHR } & \multirow{2}{*}{$P$ value } \\
\hline & $<18.5$ & $18.5-24.9$ & $25.0-29.9$ & $\geq 30.0$ & & & \\
\hline $\mathrm{ClCr} \geq 90 \mathrm{mls} / \mathrm{min}$ & $10(5.0)$ & $58(29.1)$ & $83(41.7)$ & $43(24.1)$ & 16.528 & 0.011 & 0.026 \\
\hline $60-89$ & $14(9.8)$ & $54(37.8)$ & 47 (32.9) & $28(19.6)$ & & & \\
\hline $30-60$ & $0(0)$ & $16(48.5)$ & 1442.4) & $3(4.1)$ & & & \\
\hline CD4 cells $\leq 200$ & $1(2.0)$ & $15(30.6)$ & $28(57.1)$ & $5(10.2)$ & 10,241 & 0.013 & 0.017 \\
\hline$>200$ & $23(6.7)$ & $119(34.7)$ & $122(35.6)$ & $79(13.3)$ & & & \\
\hline $24 \mathrm{HUP}<0.300 \mathrm{~g}$ & 13 (3.9) & $123(36.9)$ & $130(39.0)$ & $67(20.1)$ & 42,581 & $<0.001$ & $<0.001$ \\
\hline$\geq 0.300 \mathrm{~g}$ & $13(24.1)$ & 15 (27.3?) & $14(25.9)$ & $12(22.2)$ & & & \\
\hline ChollT des $(<5.2)$ & $20(6.0)$ & $119(34.2)$ & $141(40.5)$ & $67(19.3)$ & 15,865 & 0.012 & 0.014 \\
\hline bL (5.2 - 6.2) & $3(7.7)$ & 13 (33.3) & $9(23.6)$ & 13 (35.9) & & & \\
\hline High $(>6.2)$ & $0(0)$ & $2(33.3)$ & $0(0)$ & $4(66.7)$ & & & \\
\hline LDL-C des $(<2.6)$ & $21(6.5)$ & $110(34.1)$ & 125 (38.7) & 67 (20.7) & 932 & 0.811 & 0.918 \\
\hline bL (2.6 - 4.1) & $3(4.3)$ & $24(34.8)$ & $25(36.2)$ & 17 (24.6) & & & \\
\hline HDL-Cdes $(<1.0)$ & $9(6.7)$ & $41(30.4)$ & $61(45.2)$ & $24(17.8)$ & 5006 & 0.172 & 0.171 \\
\hline High $(>1.0)$ & $15(5.8)$ & 93 (36.2) & 89 (34.5) & $61(23.6)$ & & & \\
\hline TG des $(<1.7)$ & $24(6.8)$ & 118 (33.3) & $138(39.0)$ & 74 (20.9) & 9771 & 0.212 & 0.369 \\
\hline bL (1.7 - 2.2) & $0(0)$ & 13 (43.3) & $10(33.3)$ & $7(23.3)$ & & & \\
\hline High $(>2.2)$ & $0(0)$ & $3(37.5)$ & $1(12.5)$ & $4(50.0)$ & & & \\
\hline
\end{tabular}

$\Lambda^{2}=$ chi square, $\mathrm{LHR}=$ likelihood ratio, $\mathrm{ClCr}=$ creatinine clearance, $24 \mathrm{HUP}=24$-hor urine protein, CholT = serum total cholesterol, $\mathrm{LDL}$-C = serum low density lipoprotein cholesterol, HDL-C = serum high density lipoprotein cholesterol, TG = serum triglyceride, des = desirable level, bL = borderline.

ese subjects, $10.1 \%$ have 24HUP 0.150 - 0.300 g, while $15.2 \%$ have 24 HUP 0.301 - 3.499 g, indicating also that the prevalence of obesity increased as proteinuria increased.

There was significant association between cholesterol and different levels of BMI in HIV subjects, $\mathrm{p}=0.014$. Out of 24 underweight subjects, $16.7 \%$ have cholesterol $\geq 5.2 \mathrm{mmol} / \mathrm{l}$ while $83.3 \%$ have cholesterol < 5.2 $\mathrm{mmol} / \mathrm{l}$, demonstrating that the prevalence of underweight declined as cholesterol increased. Similarly, out of 84 obese subjects, $21.4 \%$ have cholesterol $\geq 5.2 \mathrm{mmol} / \mathrm{l}$, while $78.6 \%$ have cholesterol $<5.2 \mathrm{mmol} / \mathrm{l}$, demonstrating that the prevalence of obesity declined as cholesterol increased. Among those who have cholesterol desirable level < $5.2 \mathrm{mmol} / \mathrm{l}$, underweight was 20 (6.0\%), overweight was 14 (40.5\%) and obese was 67 (19.35). This showed that underweight subjects constituted the least proportion of those with desirable serum cholesterol.

There was no significant association between different levels of BMI and LDL, $\mathrm{p}=0.918, \mathrm{HDL}, \mathrm{p}=0.171$, and triglyceride, $\mathrm{p}=0.369$, in HIV subjects.

Table 3 shows that BMI has significant correlation with SUP $(r=-0.138, p=0.006)$, SUCr $(r=0.131, p=$ 0.009), 24HUP ( $r=-0.171, p=0.001), 24 H U O s m(r=0.183$, $p<0.011)$, CD4 $(r=0.137, p=0.006)$, serum cholesterol ( $r=0.211$, $\mathrm{p}<0.001)$, hemoglobin $(\mathrm{r}=0.344, \mathrm{p}<0.001)$, in HIV subjects.

There was no significant correlation between BMI and SUCr, p $=0.220,24 \mathrm{HUCr} p=0.125, \mathrm{SUCOR}, \mathrm{p}=$ 0.603, triglyceride, $\mathrm{p}=0.641$, HDL, $\mathrm{p}=0.391$, LDL, $\mathrm{p}=0.053$, and ClCr, $\mathrm{p}=0.475$.

Table 4 shows a multivariate linear regression analysis of the potential risk factors with BMI in HIV subjects. High SUCr, high 24HUOsm, high serum cholesterol and high hemoglobin predicted BMI in HIV subjects. Further multivariate linear regression analysis of underweight, obesity with potential risk factors is shown in Table 5. Low 24HUOsm predicted underweight, whereas low 24HUP and high 24HUOsm predicted obesity in HIV subjects.

\section{Discussion}

In this study, the prevalence of underweight was 6.1\%, overweight $38.4 \%$ and obesity $21.5 \%$ in newly-diagnosed HIV subjects. BMI changes have significant association with ClCr ( $\mathrm{p}=0.026)$, CD4 (p = 0.017), 24HUP (p < 
Table 3. Correlation of BMI with selected variables in HIV subjects.

\begin{tabular}{ccc}
\hline Variables & Correlation coefficient(r) & P value \\
\hline Spot urine protein & -0.138 & 0.006 \\
Spot urine creatinine & 0.131 & 0.009 \\
Spot urine osmolality & 0.082 & 0.220 \\
24-hour urine protein & -0.171 & 0.001 \\
24-hour urine creatinine & 0.079 & 0.125 \\
24-hour urine osmolality & 0.183 & $<0.001$ \\
SUCOR & 0.126 & 0.603 \\
CD4 & 0.137 & 0.006 \\
Serum cholesterol (total) & 0.211 & $<0.001$ \\
Serum triglyceride & 0.023 & 0.641 \\
Serum HDL-C & 0.043 & 0.391 \\
Serum LDL-C & 0.198 & 0.053 \\
Creatinine clearance & 0.037 & 0.475 \\
Hemoglobin & 0.344 & $<0.001$
\end{tabular}

BMI = body mass index, SUCOR = spot urine creatinine osmolality ratio, HDL-C = high density lipoprotein cholesterol, LDL-C = low density lipoprotein cholesterol.

Table 4. Multivariate linear regression of variables with BMI in HIV subjects.

\begin{tabular}{cccc}
\hline Variables & Beta & T & P value \\
\hline Spot urine protein & -0.138 & -0.441 & 0.150 \\
Spot urine creatinine & 0.131 & 2.198 & 0.029 \\
24-hour urine protein & -0.171 & -0.655 & 0.513 \\
24-hour urine osmolality & 0.183 & 2.456 & 0.001 \\
CD4 cells & 0.137 & 0.247 & 0.805 \\
Serum cholesterol (total) & 0.211 & 4.606 & $<0.001$ \\
Hemoglobin & 0.344 & 8.785 & $<0.001$ \\
\hline
\end{tabular}

BMI = body mass index

Table 5. Multivariate linear regression of variables with underweight and Obesity in HIV subjects.

\begin{tabular}{|c|c|c|c|c|c|c|}
\hline \multirow{2}{*}{ Variables } & \multicolumn{3}{|c|}{ Underweight (BMI < 18.5) } & \multicolumn{3}{|c|}{ Obesity (BMI $\geq 30$ ) } \\
\hline & Beta & $\mathbf{t}$ & $P$ value & Beta & $\mathbf{T}$ & P value \\
\hline SUP & -0.107 & -0.421 & 0.674 & -0.087 & -0.677 & 0.500 \\
\hline SUCr & 0.357 & 1.384 & 0.185 & 0.049 & 0.384 & 0.702 \\
\hline 24HUP & -0.176 & -0.798 & 0.436 & -0.216 & -2.012 & 0.048 \\
\hline 24HUOsm & -0.830 & -5.770 & $<0.001$ & 0.430 & 3.364 & 0.001 \\
\hline CD4 cells & 0.196 & 1.079 & 0.296 & -0.131 & -1.099 & 0.275 \\
\hline Cholesterol & 0.352 & 1.203 & 0.246 & 0.103 & 0.875 & 0.384 \\
\hline Hemoglobin & 0.112 & 0.456 & 0.655 & 0.118 & 1.102 & 0.274 \\
\hline
\end{tabular}

$\mathrm{BMI}=$ body mass index, SUP = spot urine protein, $\mathrm{SUCr}=$ spot urine creatinine, $24 \mathrm{HUP}=24$-hour urine protein, $24 \mathrm{HUOsm}=24$-hour urine osmolality.

0.001), cholesterol (0.014). High SUCr $(p=0.029)$, high 24HUOsm $(p=0.001)$, high serum cholesterol $(p<$ $0.001)$ and high hemoglobin ( $p<0.001)$ were predictors of BMI in HIV subjects. Low 24HUOsm $(p<0.001)$ was a predictor of underweight, whereas low 24HUP $(p=0.001)$ and high 24HUOsm $(p=0.001)$ were predictors of obesity in HIV subjects. 
The prevalence of underweight $6.1 \%$ in HIV subjects observed in this study is slightly lower than the $8.8 \%$ reported by Carolline de Araújo MarizI et al. in Brazil [10]. This observed slight difference in prevalence might be explained by the difference in the size of the study population. Their study involved 2018 subjects, whereas ours was 393. However, a report by Kwiatkowska et al. [20] showed a prevalence of $6.8 \%$ in a study involving 72 subjects in Poland [20], a prevalence similar to our finding. In a related study in HAART-treated subjects [21], the prevalence of underweight $2.0 \%$ was lower than that obtained in our study. This showed that HIV subjects on HAART have less underweight than those who were not on HAART [21].

On the contrary, the prevalence of overweight $38.4 \%$ and obesity $21.5 \%$ noted in this study are similar to those reported in two studies, one in Brazil [10], the other in USA [22]. These, including our findings, are similar to the BMI reported in a general population in Eastern Nigeria [23]. The high prevalence of obesity observed in our study in subjects who were not on HAART, might be explained by a background high prevalence of obesity in the general population [23].

In this study, low SUP was associated with BMI, $(r=-0.138, p=0.006)$, but did not predict BMI, $p=0.150$. From literature search we could not find any previous study that evaluated SUP in BMI in HIV subjects.

This study demonstrated that SUCr was a predictor of BMI in HIV subjects. This indicated that low SUCr was related to declining BMI including underweight, while high SUCr was related to increasing BMI including obesity. However, the study further demonstrated that SUCr was not a predictor of isolated underweight, nor was it a predictor of isolated obesity. Although SUCr varies over 24 hours, low SUCr reflects low excretion of creatinine in urine, and this may quantitatively indicate kidney damage [24]. Therefore, SUCr as a predictor of BMI in HIV subjects in this study implied that underweight HIV subjects were more likely to have kidney damage.

ClCr was significantly associated with BMI changes, $p=0.026$, but was not a predictor of BMI in HIV subjects in this study. This study also showed that underweight HIV subjects constituted the smallest proportion of those who have normal ClCr. We did not find, from literature search, any study on BMI in HIV subjects that assessed SUCr or ClCr.

We found that 24HUP was associated with BMI changes $(\mathrm{p}<0.001)$ but did not predict BMI $(\mathrm{p}=0.513)$ in this study. However, the study demonstrated that low 24HUP was a predictor of isolated obesity, $\mathrm{p}=0.048$. This showed that obese HIV subjects were less likely to have significant proteinuria. However, literature search did not reveal any study that evaluated the association of proteinuria with BMI in HIV subjects.

Our study showed that 24HUOsm was a predictor of BMI in HIV subjects. However, low 24HUOsm was a predictor of underweight, while high 24HUOsm was a predictor of obesity. Low 24HUOsm may indicate inability of the kidney to concentrate urine, which may be observed in kidney damage that involves the interstitial compartment and the distal tubules. We could not find any study on 24HUOsm in BMI in HIV, from literature search. However, a study demonstrated that high 24HUOsm was associated with HIV infection [25], in contrast to another study that reported low 24HUOsm in HIV infection [26].

CD4 cells count was associated with BMI changes, $\mathrm{p}=0.017$, but did not predict BMI, $\mathrm{p}=0.805$, in HIV subjects in this study. We also observed that underweight subjects constituted the smallest proportion of those with CD4 $\geq 200$ cells/ml. This finding is in agreement with those reported in some studies in which CD4 < 200 cells/ml was associated with underweight in an HIV population [10] [27].

We showed that serum total cholesterol was a predictor of BMI in HIV subjects in this study. However, serum cholesterol did not predict isolated underweight, $\mathrm{p}=0.246$, and did not predict isolated obesity, $\mathrm{p}=0.384$, either. We also noted that underweight subjects constituted the least proportion of those with desirable serum cholesterol. Literature search did not reveal any lipid studies in BMI in the early phases of HIV infection. However, abnormalities of serum cholesterol were shown in HIV subjects, especially those on HAART [26] [28].

In this study, hemoglobin was a predictor of BMI in HIV subjects. However, hemoglobin was not a predictor of isolated underweight, $\mathrm{p}=0.655$ as well as isolated obesity, $\mathrm{p}=0.214$. This observation is similar to a report that also documented anemia associated with weight changes in HIV subjects [10].

The study showed that there was no association between BMI and SUOsm, 24HUCr, SUCOR, HDL, LDL, triglyceride, in HIV subjects.

\section{Conclusion}

The prevalence of underweight was low (6.1\%), overweight high (38.4\%) and obesity high (21.5\%) in HIV subjects. High SUCr, high 24HUOsm, high serum cholesterol and high hemoglobin were predictors of BMI in the 
HIV subjects. Low 24HUOsm was a predictor of underweight, while low 24HUP and high 24HUOsm were predictors of obesity in HIV subjects. Abnormalities of serum lipids, renal function, and anemia were common in HIV subjects who were underweight and those obese. Underweight HIV subjects should be evaluated at the early stages for dyslipidemia, renal damage and anemia.

\section{References}

[1] UNAiDS (2013) Global Report: UNAIDS Report on the Global AIDS Epidemic.

[2] van der Sande, M.A., Schim van der Loeff, M.F., Aveika, A.A., Sabally, S., Togun, T., Sarge-Njie, R., Alabi, A.S., Jaye, A., Corrah, T. and Whittle, H.C. (2004) Body Mass Index at Time of HIV Diagnosis: A Strong and Independent Predictor of Survival. Journal of Acquired Immune Deficiency Syndromes, 37, 1288-1294. http://dx.doi.org/10.1097/01.qai.0000122708.59121.03

[3] Tang, A.M. (2003) Weight Loss, Wasting, and Survival in HIV-Positive Patients: Current Strategies. AIDS, 13, S23S27.

[4] American Diabetes Association (2004) Position of the American Dietetic Association and Dietitians of Canada: Nutrition Intervention in the Care of Persons with Human Immunodeficiency Virus Infection. Journal of the American Dietetic Association, 104, 1425-1441. http://dx.doi.org/10.1016/j.jada.2004.07.012

[5] Madeddu, G., Spanu, A., Solinas, P., Calia, G.M., Lovigu, C., Chessa, F., et al. (2004) Bone Mass Loss and Vitamin D Metabolism Impairment in HIV Patients Receiving Highly Active Antiretroviral Therapy. The Quarterly Journal of Nuclear Medicine and Molecular Imaging, 48, 39-48.

[6] Dutra, C.D.T. and Libonati, M.F. (2008) Abordagemmetabólica e nutricional da lipodistrofiaemuso da terapia anti-retroviral. Revista de Nutrição, 21, 239-246. http://dx.doi.org/10.1590/S1415-52732008000400008

[7] Maas, J.J., Dukers, N., Krol, A., van Ameijden, E.J., van Leeuwen, R., Roos, M.T., de Wolf, F., Coutinho, R.A. and Keet, I.P. (1998) Body Mass Index Course in Asymptomatic HIV-Infected Homosexual Men and the Predictive Value of a Decrease of Body Mass Index for Progression to AIDS. Journal of Acquired Immune Deficiency Syndromes and Human Retrovirology, 19, 254-259. http://dx.doi.org/10.1097/00042560-199811010-00007

[8] Jaime, P.C., Florindo, A.A., Latorre, M.R.D.O., Brasil, B.G., Santos, E.C.M. and Segurado, A.A.V. (2004) Prevalence of Overweight and Central Obesity in HIV/AIDS Patients Treated with Highly Active Antiretroviral Therapy. Revista Brasileira de Epidemiologia, 7, 65-72.

[9] Leite, L.H.M. and Sampaio, A.B.M.M. (2008) Metabolic Abnormalities and Overweight in HIV/AIDS Persons Treated with Antiretroviral Therapy. Revista de Nutrição, 21, 277-283. http://dx.doi.org/10.1590/S1415-52732008000300002

[10] Carolline de Araújo, M., Maria de Fátima, P., de Albuquerque, M.., de Alencar, R.A., de Melo, H.R.L.; Bandeira, F; de Oliveira, T.G.B., de Carvalho, É.H., da Silva, A.P. and de Barros Miranda Filho, D. (2011) Body Mass Index in Individuals with HIV Infection and Factors Associated with Thinness and Overweight/Obesity. Cadernos de Saúde Pública, 27.

[11] Hendricks, K.M., Mwamburi, D.M., Newby, P.K. and Wanke, C.A. (2008) Dietary Patterns and Health and Nutrition Outcomes in Men Living with HIV Infection. The American Journal of Clinical Nutrition, 88, 1584-1592. http://dx.doi.org/10.3945/ajcn.2008.26098

[12] Ford, E.S. and Mokdad, A.H. (2008) Epidemiologia da obesidade no hemisférioocidental. Centers for Disease Control and Prevention, Atlanta.

[13] Oliveira, O.M.V., Medeiros, R.S., Nascimento, M.A.B. and Boni, M.S. (2008) Perfilnutricional e fatores de riscoparaobesidade central de pessoasquevivem com HIV/AIDS. Comunicação em Ciências da Saúd, 19, 305-314.

[14] Rocha, P.B. and Schuch, I. (2009) Perfilalimentar e nutricional dos pacientes HIV positivoatendidosem um serviçopúblico de saúde de Porto Alegre/RS. Nutrire: Revista da Sociedade Brasileira de Alimentação e Nutrição, 34, 115.

[15] Graham, N.M., Muñoz, A., Bacellar, H., Kingsley, L.A., Visscher, B.R. and Phair, J.P. (1993) Clinical Factors Associated with Weight Loss Related to Infection with Human Immunodeficiency Virus Type 1 in the Multicenter AIDS Cohort Study. American Journal of Epidemiology, 137, 439-446.

[16] Smit, E., Skolasky, R.L., Dobs, A.S., Calhoun, B.C., Visscher, B.R., Palella, F.J. and Jacobson, L.P. (2002) Changes in the Incidence and Predictors of Wasting Syndrome Related to Human Immunodeficiency Virus Infection, 1987-1999. American Journal of Epidemiology, 156, 211-218. http://dx.doi.org/10.1093/aje/kwf039

[17] Gigante, D.P., Moura, E.C. and Sardinha, L.M.V. (2009) Prevalence of Overweight and Obesity and Associated Factors, Brazil, 2006. Revista de Saúde Pública, 43, 83-89. http://dx.doi.org/10.1590/S0034-89102009000900011

[18] Federal Republic of Nigeria Global AIDS Response and Progress Report 2012. 
[19] WHO (1995) Physical Status: The Use and Interpretation of Anthropometry. Technical Report Series 854, 1-1-9950. World Health Organization, Geneva.

[20] Kwiatkowska, W., Knysz, B., Drelichowska-Durawa, J., Czarnecki, M., Gasiorowski, J., Biłyk, E., Karczewski, M. and Witkiewicz, W. (2013) Overweight, Obesity and Underweight in HIV Infected Patients. Przeglad Lekarski, 70, 113117.

[21] Crum-Cianflone, N., Roediger, M.P., Eberly, L., Headd, M., Marconi, V., Ganesan, A., et al. (2010) Increasing Rates of Obesity among HIV-Infected Persons during the HIV Epidemic. PLoS ONE, 5, e10106. http://dx.doi.org/10.1371/journal.pone.0010106

[22] Tate, T., Willig, A.L., Willig, J.H., Raper, J.L., Moneyham, L., Kempf, M.C., Saag, M.S. and Mugavero, M. (2012) HIV Infection and Obesity: Where Did All the Wasting Go? Antiviral Therapy, 17, 1281-1289. http://dx.doi.org/10.3851/IMP2348

[23] Chukwuonye, I., Chuku, A., Onyeonoro, U., Ukegbu, A., Anyabolu, E., Okpechi, I., Madukwe, O.O. and Ogah, O.S. (2015) Body Mass Index, Prevalence and Predictors of Obesity in Urban and Rural Communities in Abia State South Eastern Nigeria. Journal of Diabetes \& Metabolism, 6, 570. http://dx.doi.org/10.4172/2155-6156.1000570

[24] Anyabolu, E.N., Chukwuonye, I.I., Arodiwe, E., Jjoma, C.K. and Ulasi, I. (2016) Prevalence and Predictors of Chronic Kidney Disease in Newly-Diagnosed Human Immunodeficiency Virus Patients in Owerri, Nigeria. Indian Journal of Nephrology, 26, 10-15. http://www.indianjnephrol.org/preprintarticle.asp?id=156115

[25] Waldo, H.B., Mariana de Paz, S., Matilde, N., Marisa, L. and Aeiel, G. (2014) Impaired Urine Dilution Capability in HIV Stable Patients. International Journal of Nephrology, 2014, Article ID: 381985.

[26] Anyabolu, E.N., Chukwuonye, I.I., Anyabolu, A.E. and Enwere, O.O. (2015) A Study of Clinical and Biochemical Profiles of HIV Patients in Owerri, Southeast Nigeria. Journal of Medical Science and Clinical Research, 3, 86438650 .

[27] Boodram, B., Plankey, M.W., Cox, C., Tien, P.C., Cohen, M.H., Anastos, K., Karim, R., Hyman, C. and Hershow, R.C. (2009) Prevalence and Correlates of Elevated Body Mass Index among HIV-Positive and HIV-Negative Women in the Women's Interagency HIV Study. AIDS Patient Care and STDs, 23, 1009-1016. http://dx.doi.org/10.1089/apc.2009.0175

[28] Malapati, B., Bhavita Patel, B., Shah, R.M., Nillawar, A.N., Latha, M., Vajrala, D. and Shaikh, N. (2014) Changes in Lipid Profile and Other Biochemical Parameters in HIV-1 Infected Patients. International Journal of Medical Science and Public Health, 3, 813-817. http://dx.doi.org/10.5455/ijmsph.2014.220420144

\author{
Abbreviations \\ BMI: body mass index \\ ClCr: creatinine clearance \\ FMC: Federal Medical Centre \\ FSLP: fasting serum lipid profile \\ $\mathrm{Hb}$ : hemoglobin \\ HDL: high density lipoprotein cholesterol \\ HIV: human immunodeficiency virus \\ LDL: low density lipoprotein cholesterol \\ SCr: serum creatinine \\ SUCOR: spot urine creatinine/osmolality ratio \\ SUOsm: spot urine osmolality \\ SUP: spot urine protein \\ 24HUCOR: 24-hour urine creatinine/osmolality ratio \\ 24HUCr: 24-hour urine creatinine \\ 24HUOsm: 24-hour urine osmolality \\ 24HUP: 24-hour urine protein
}

